\title{
Correction to: Co-enzyme Q10 and acetyl salicylic acid enhance Hsp70 expression in primary chicken myocardial cells to protect the cells during heat stress
}

Jiao Xu ${ }^{1} \cdot$ Shu Tang ${ }^{1} \cdot$ Bin Yin ${ }^{1} \cdot$ Jiarui Sun ${ }^{1} \cdot$ Erbao Song $^{1} \cdot$ Endong Bao $^{1}$

Published online: 27 September 2019

(c) Springer Science+Business Media, LLC, part of Springer Nature 2019

Correction to: Mol Cell Biochem (2017) 435:73-86

https://doi.org/10.1007/s1 1010-017-3058-1

In the original publication of the article, one of the images was selected by mistake in Fig. 3 (HS + ASA, 5 h). The correct version of Fig. 3 is given in this correction.

The original article can be found online at https://doi.org/10.1007/ s11010-017-3058-1.

Endong Bao

b_endong@njau.edu.cn

1 College of Veterinary Medicine, Nanjing Agricultural

University, Weigang 1, Nanjing 210095, China 
HS

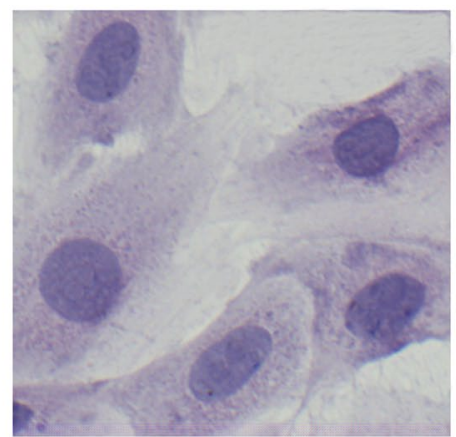

oh

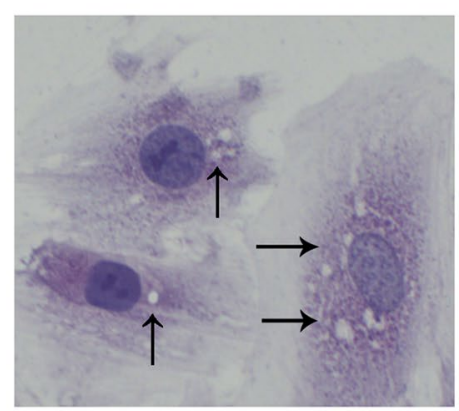

HS + Q10
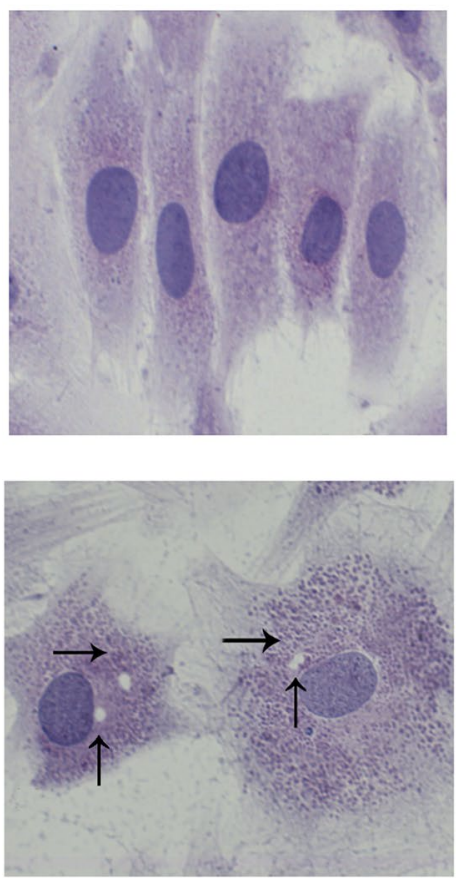

HS+ASA
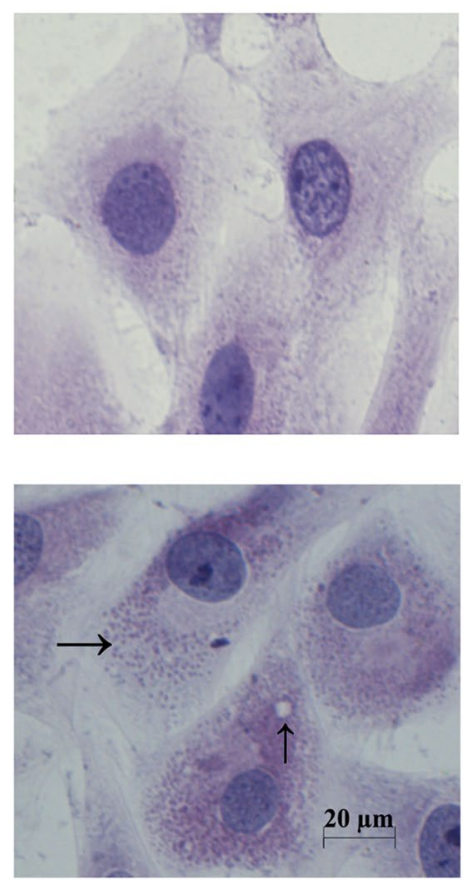

Fig. 3 Pathological changes observed during heat stress $(1 \mathrm{bar}=20 \mathrm{~lm})$. No obvious lesions were observed in the absence of heat stress. After $5 \mathrm{~h}$ heat stress, granular degeneration (rightwards arrow) appeared in cytoplasm, and more severe vacuolar degeneration (upwards arrow) was found in heat stress groups (evidenced by honeycomb shaped appearance of myocardial cells)

Publisher's Note Springer Nature remains neutral with regard to jurisdictional claims in published maps and institutional affiliations. 